\title{
Geopolymer Cement Based on Alkali Activated Slag
}

Essam A. Kishar, Doaa A. Ahmed, Nourhan Nabil

Chemistry Department, University College, For Girls.

Ain Shams University, Cairo, Egypt.

\begin{abstract}
The aim of this investigation is to prepare geopolymer cement by mixing various amounts of granulated blast furnace slag (GBFS) with Fly ash (FA) and cement kiln dust (CKD). Seven blends are prepared using $100 \%$ slag , 95\% slag+5\% CKD or fly ash, 90\% slag $+10 \%$ CKD or Fly ash and $85 \%$ slag $+15 \%$ CKD or Fly ash . The dry mixes with the different mixing ratios are activated by the alkaline activator (AA) 6\% sodium hydroxide solution and $10 \%$ by volume liquid sodium silicate, the w/s ratio used is 0.24 . The pastes are moulded into 1 inch cubic moulds and left within the moulds at $100 \%$ relative humidity for $24 \mathrm{hrs}$, then demoulded and cured under tap water for 1,3,7,28,90 and 180 days. At each hydration time, compressive strength, combined water, bulk density, total porosity are determined . X-ray diffraction measurements showed CSH as the main hydration constituent of the geopolymer structure being amorphous and glass-like. The results indicate that the mix containing $85 \%$ slag $+15 \%$ fly ash give the best physico chemical and mechanical properties of geopolymer cement .
\end{abstract}

Keywords: Geopolymer cement, Slag, Fly ash, Cement kiln dust and Alkali activated binders.

Corresponding author : nouranabil.eg@gmail.com 


\section{Introduction}

Cement has been widely used as construction materials. Currently, the world annual consumption of Ordinary Portland Cement (OPC) is about 1.56 billion tons (Cement Statistics .2000). One main byproduct of cement production is $\mathrm{CO}_{2}$, a major greenhouse emission. In total, it accounts for around $7 \%$ of the atmosphere's $\mathrm{CO}_{2}$ loading. Overall, the production of OPC is a high temperature, energy consuming and heavily polluting process; Every ton of OPC produced releases 800 kilograms of $\mathrm{CO}_{2}$ ( Crow and JM.,2008).

All of these conditions have led to look into alternative materials with high compressive strength that are also cheap and more environmentally friendly to use as a building materials. A new building material being researched is geopolymer cement. A major advantage of using geopolymers over OPC is that the raw materials are industrial waste products and the manufacturing process is more environmental friendly .

Geopolymer is a type of amorphous alumino-silicate cementitious material. Geopolymer can be synthesized by polycondensation reaction of geopolymeric precursor and alkali poly silicates known as geopolymerization process. Geopolymerization is an innovative technology that can transform several alumino silicate materials into useful products called geopolymers or inorganic polymers (Dimas et al .,2009) .

The geopolymerization process involves a substantially fast chemical reaction under alkaline condition on $\mathrm{Si}-\mathrm{Al}$ minerals that result in a three dimensional polymeric chain and ring structure consisting of $\mathrm{Si}-\mathrm{O}-\mathrm{Al}-\mathrm{O}$ bonds, as follows:

$$
\mathrm{M}_{\mathrm{n}}\left[-\left(\mathrm{SiO}_{2}\right)_{\mathrm{z}}-\mathrm{AlO}_{2}\right]_{\mathrm{n}} \cdot \mathrm{wH}_{2} \mathrm{O}
$$

Where: $\mathrm{M}=$ the alkaline element or cation such as potassium, sodium or calcium,

$\mathrm{n}=$ the degree of poly condensation or polymerization,

$\mathrm{z}=1,2,3$ or higher.

$\mathrm{w}=$ number of water molecules

The proposed mechanism of geopolymer consists of the chemical reaction may comprise the following steps: (1) Dissolution of $\mathrm{Si}$ and $\mathrm{Al}$ ions from the source material through the action of hydroxide ions. (2) Transportation or orientation or condensation of precursor ions into monomers. (3) Setting or polycondensation /polymerization of monomers into polymeric structures (Chanh et al.,2008). 
Starting material plays an important role in the formation of geopolymer such as calcined clays (Yunsheng et al.,2010) industrial waste (Hardjito and Shaw Shen., 2012) slag (Cheng and Chiu ., 2003) waste glass (Badanoiu et al.,2015) and many other natural and artificial silico aluminates (Zhenget al.,2015) the rice husk ash as source of amorphous silica and its calcination as waste treatment ( Tchakouté et al., 2016a,b) . The raw materials used to make geopolymers is aluminosilicates which is rich in alumina $\left(\mathrm{Al}_{2} \mathrm{O}_{3}\right)$ and silica $\left(\mathrm{SiO}_{2}\right)$.

The most common alkaline activator used in geopolymerisation is a combination of sodium hydroxide or potassium hydroxide and sodium silicate affect the dissolution of fly ash. Leaching of $\mathrm{Al}^{3+}$ and $\mathrm{Si}^{4+}$ ions are generally high with sodium hydroxide solution compared to potassium hydroxide solution. Therefore, alkali concentration is a significant factor in controlling the leaching of alumina and silica from fly ash particles, subsequent geopolymerization and mechanical properties of hardened geopolymer (Rattanasak and Chindaprasirt.,2009). Duchesne et al., (2010) confirmed that in presence of $\mathrm{NaOH}$ in the activating solution, the reaction proceeds more rapidly and the gel is less smooth.

\section{Experimental Work}

The materials used in this study are ,ground granulated blast-furnace slag (GGBFS), fly ash (FA), and cement kiln by-pass dust (CKD). The chemical composition of the starting materials are given in Table (1). The activator used are sodium hydroxide $(\mathrm{NaOH})$ and liquid sodium silicate $\left(\mathrm{Na}_{2} \mathrm{SiO}_{3}\right)$. Different mixes are prepared by mixing the samples with different ratios as shown in Table (2) 
Table (1): The chemical composition of starting materials

\begin{tabular}{|c|c|c|c|}
\hline Oxides, $\%$ & Slag & Fly ash & $\begin{array}{c}\text { Cement kiln } \\
\text { dust }\end{array}$ \\
\hline $\mathrm{SiO}_{2}$ & 34.10 & 63.20 & 14.16 \\
\hline $\mathrm{Al}_{2} \mathrm{O}_{3}$ & 12.40 & 26.34 & 3.98 \\
\hline $\mathrm{Fe}_{2} \mathrm{O}_{3}$ & 0.77 & 5.10 & 3.42 \\
\hline $\mathrm{CaO}$ & 42.30 & 2.20 & 53.87 \\
\hline MgO & 6.50 & 0.10 & 0.86 \\
\hline $\mathrm{SO}_{3}$ & 0.90 & 0.15 & 3.68 \\
\hline $\mathrm{K}_{2} \mathrm{O}$ & 0.35 & 0.76 & 6.62 \\
\hline $\mathrm{Na}_{2} \mathrm{O}$ & 0.26 & 0.44 & 3.01 \\
\hline $\mathrm{Cl}^{-}$ & $\mathbf{0 . 0 8}$ & 0.00 & 7.43 \\
\hline L.O.I & 1.50 & 2.30 & 2.80 \\
\hline Total & 99.16 & 100.59 & 99.83 \\
\hline
\end{tabular}

Table (2) : Mix composition of the prepared mixes.

\begin{tabular}{|c|c|c|c|c|}
\hline NO & Mix Abb & GGBFS & CKD & FA \\
\hline 1 & S & 100 & - & - \\
\hline 2 & SD1 & 95 & 5 & - \\
\hline 3 & SD2 & 90 & 10 & - \\
\hline 4 & SD3 & 85 & - & 5 \\
\hline 5 & SF1 & 95 & - & 10 \\
\hline 6 & SF2 & 90 & - & 15 \\
\hline 7 & SF3 & 85 & & \\
\hline
\end{tabular}


The alkaline activator (AA) is prepared by mixing $10 \%$ liquid sodium silicate $\left(\mathrm{Na}_{2} \mathrm{SiO}_{3}\right)$ and $6 \%$ sodium hydroxide $(\mathrm{NaOH})$, the temperature of the mixture was initially quite high then left to reach to room temperature in few minutes before proceeding. Geopolymer is obtained by the addition each dry mix to alkali activator solution with w/s ratio $=0.24$ the paste is placed in the stainless steel mold 1 - cubic inch -shaped molds. Immediately put the mold in humidifier (100\% R .H.) at room temperature (25 \pm 1$)$ for the first $24 \mathrm{hrs}$. After this period the cubes are removed from the mold and cured under tap water until the required time of testing 1,3,7,28,90, and 180 days.

The hydration characteristics of the different mixes have been tested via determination of compressive strength, combined water, bulk density, total porosity. The formed hydration products were determined by XRD analysis.

After compressive strength measurement a few grams is taken from the crushed cubes and stirred with about $100 \mathrm{ml}$ of $(1: 1 \mathrm{v} / \mathrm{v})$ of methyl alcohol and acetone to stop the hydration (Abdel Gawwad .,2010). After filtration the sample is dried at $100{ }^{\circ} \mathrm{C}$ for $24 \mathrm{hrs}$, then kept for analysis.

\section{Results and discussion}

\section{A .The mixture containing GGBFS and CKD}

\section{A.1. Compressive strength}

The compressive strength of hardened alkali activated mixes (S,SD1,SD2,SD3) cured up to 180 days in water are graphically plotted in Fig. (1). The compressive strength of all mixes increases with curing time. This is due to that the alkali contents accelerate the activation process. It is clear that the value of the compressive strength increase, this is mainly due to the higher rate of hydration as well as formation of more hydration products (CSH). 


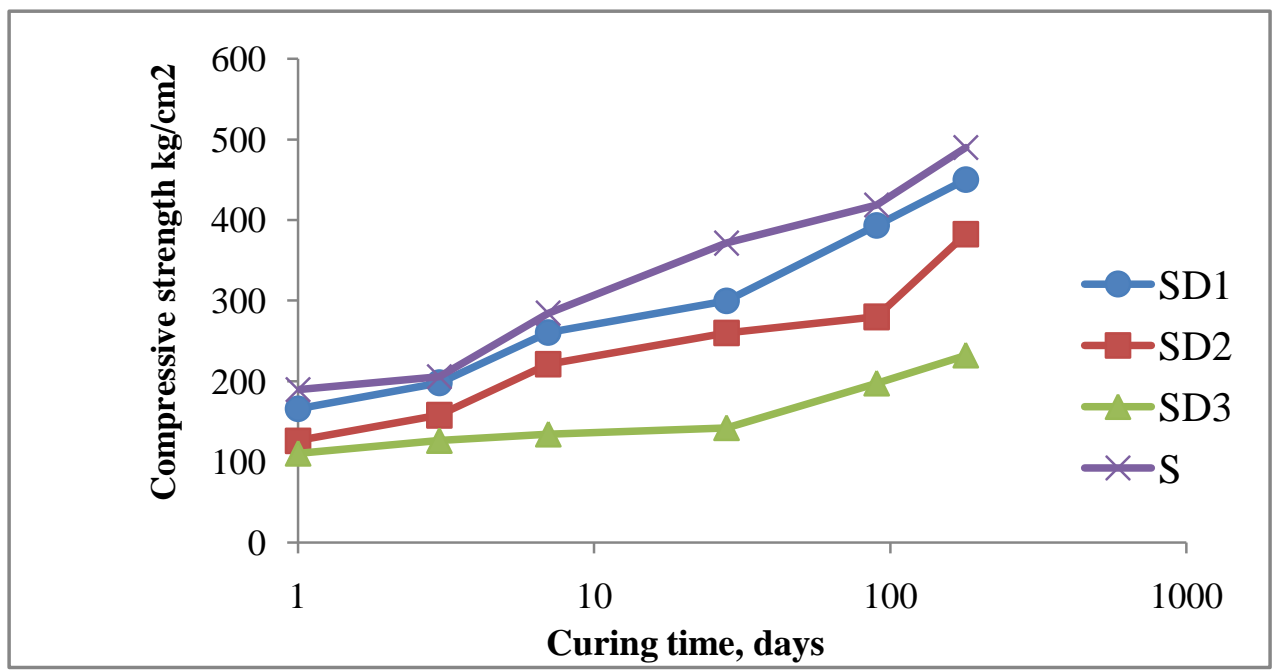

Figure (1): Compressive strength $\left(\mathrm{kg} / \mathrm{cm}^{2}\right)$ of alkali activated GBFS-CKD cured in $\mathrm{H}_{2} \mathrm{O}$ up to 180 days

\section{III.A.2. Chemically combined water content}

Chemically combined water contents $(\mathrm{Wn})$ for mixes (S, SD1,SD2,SD3) cured up to 180 days are graphically plotted in Fig.(2). The Wn content can be adopted as a criterion to evaluate the relative amount of hydration products and the relative hydration degree between different samples with the same kind of hydration products. It is clear that the combined water contents of the alkali activated GBFS pastes gradually increases up to 180 days. This is due to the continuous hydration and accumulation of hydrated products, which deposited in the available open pores. Fig. (2) also shows the Wn contents of the samples of GBFS with CKD at the different hydration ages.

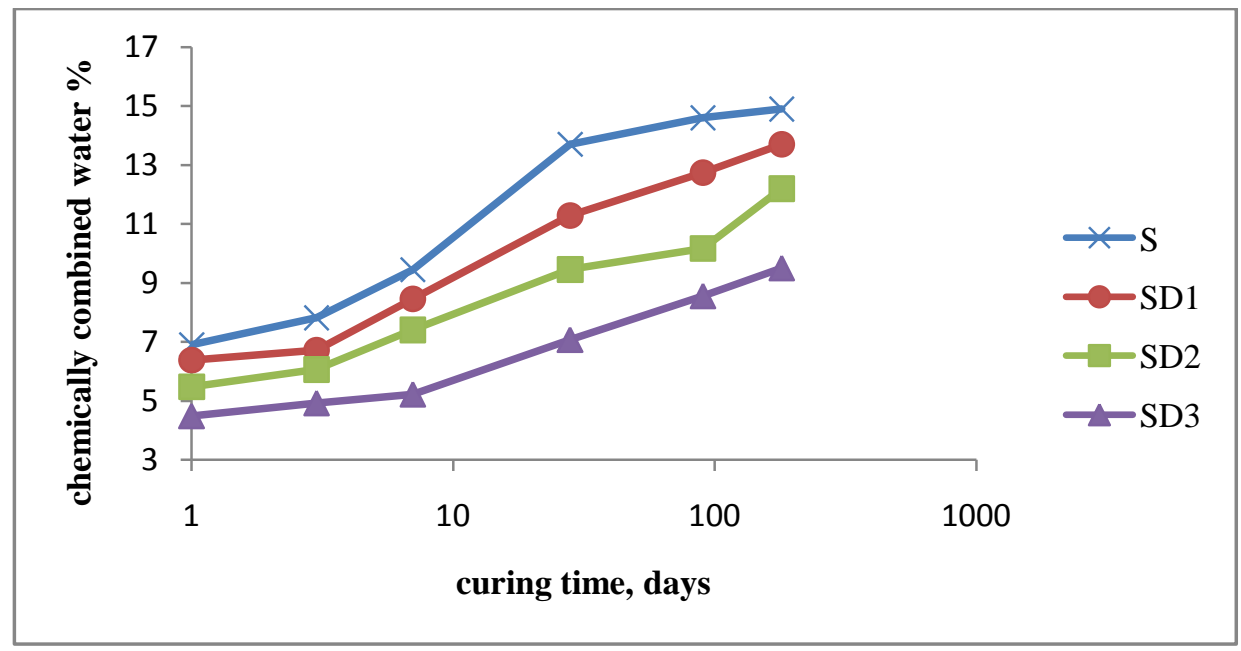

Figure (2): Chemically combined water content (\%) of alkali activated GBFS-CKD cured up to 180 days

\section{III.A.3. Bulk density}

The bulk density of hardened alkali activated mixes (S,SD1,SD2,SD3 ) cured up to 180 days in water are graphically plotted in Fig (3). The bulk density of hardened activated GBFS increases with curing time up to 180 days. The bulk density of alkali activated GBFS increases due to the continuous activation and formation of hydrated products. These hydrated products are deposited in the open pores that increase the bulk density of the activated slag. 
The alkali activator enhances the production of higher concentration of $[\mathrm{SiO} 4]^{-4}$ which increases the rate of hydration and formation of more CSH and CASH. Therefore the bulk density accordingly increases; this is mainly due to the formation of large amounts of hydration products.

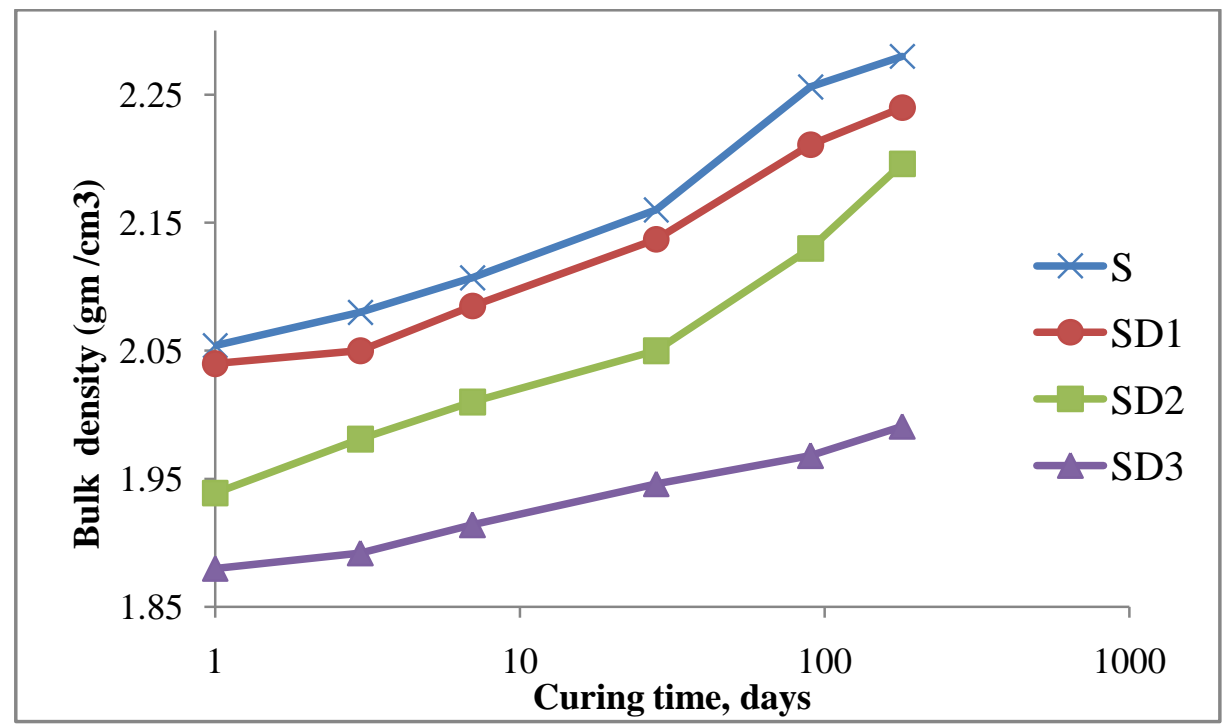

Figure (3): Bulk density $\left(\mathrm{g} / \mathrm{cm}^{3}\right)$ of alkali activated GBFS-CKD cured up to 180 days.

\section{III.A.4. Total porosity}

The total porosity for mixes (S,SD1,SD2,SD3) are graphically plotted in Fig. (4). It is clear that the total porosity decrease with curing time due to the formation and deposition of the hydration products in the pore structure of the hardened activated pastes.

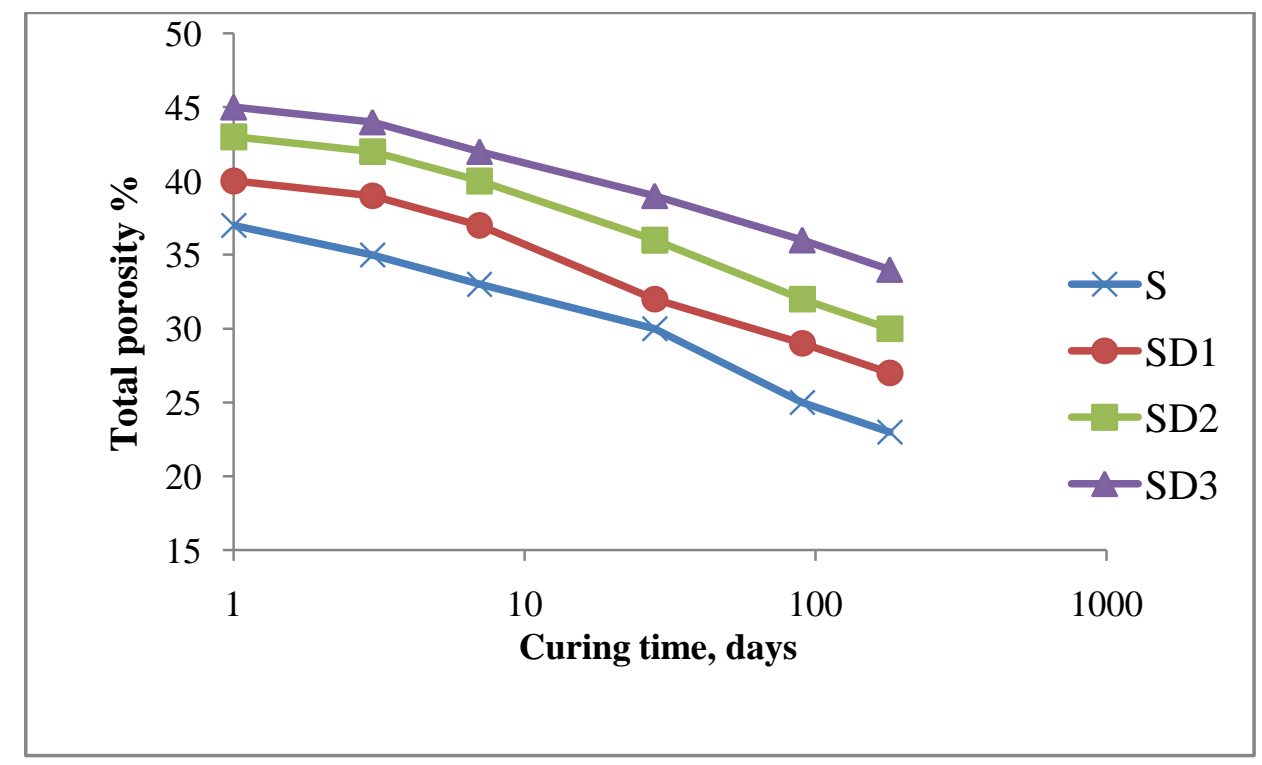

Figure (4): Total porosity (\%) of alkali activated GBFS-CKD cured up to 180 day 


\section{III.A.5. X-ray diffraction analysis}

XRD patterns of alkali activated (SD 1- SD 2-SD3) are shown in Figs. (5,6,7), it can be observed that the hump peak in the range of $25-35^{\circ}, 2 \Theta$ changes with curing time up to 180 days, suggesting that poor crystalline $\mathrm{CSH}$ gel produced in the pastes. Indeed, once GBFS-CKD powder is mixed with the alkaline solution, geopolymer gel and CSH gel could be formed after setting and hardening.

In alkali activated GBFS-CKD, the presence of the strong peak at $d=3.07 \mathrm{~A}^{\mathrm{o}}$ is attributed to $\mathrm{CSH}$ phases, which are composed of calcium silicate hydrate.

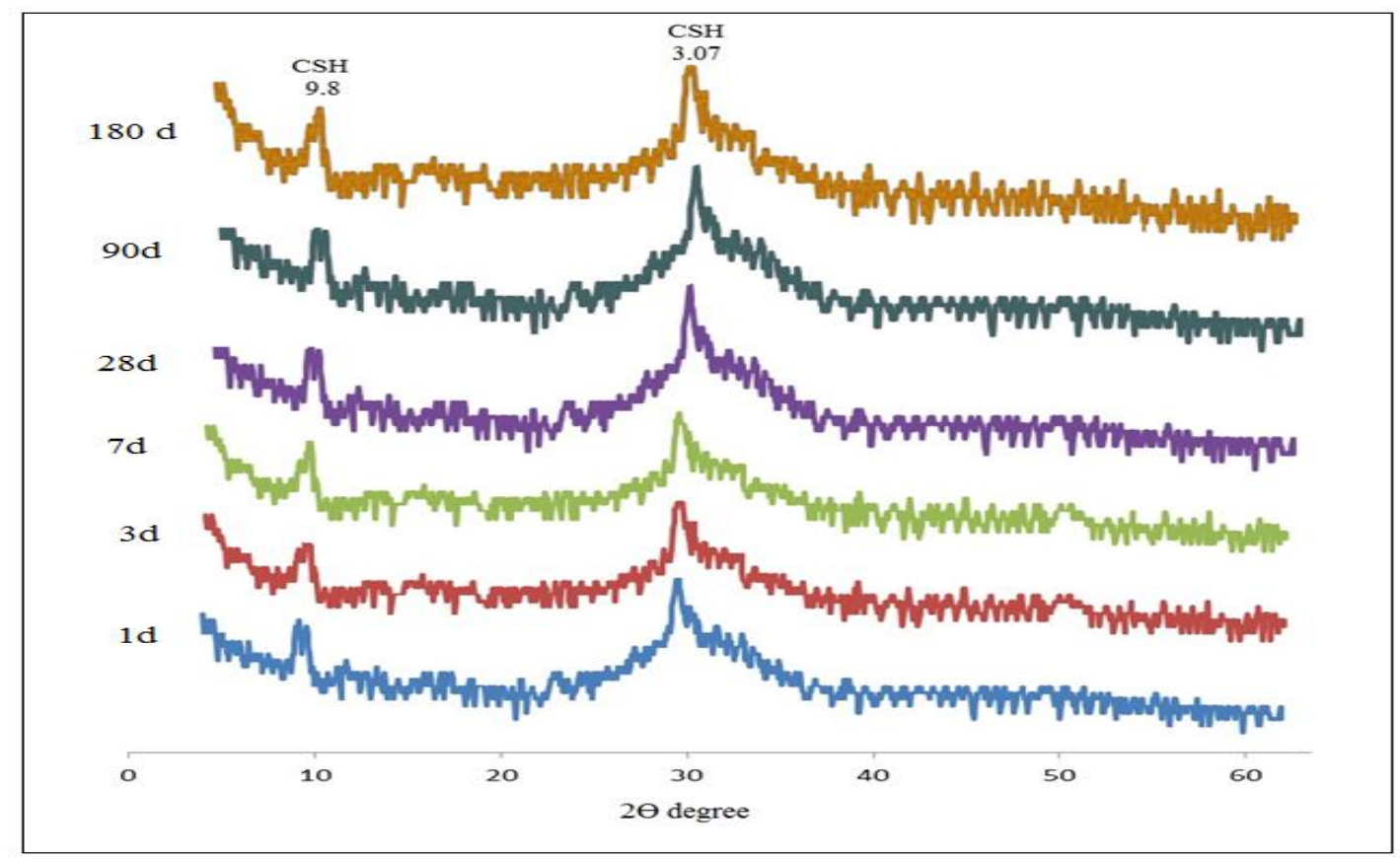

Figure (5): X-ray diffraction patterns for mixes contain (95\% GBFS+ 5\%CKD) (SD1)

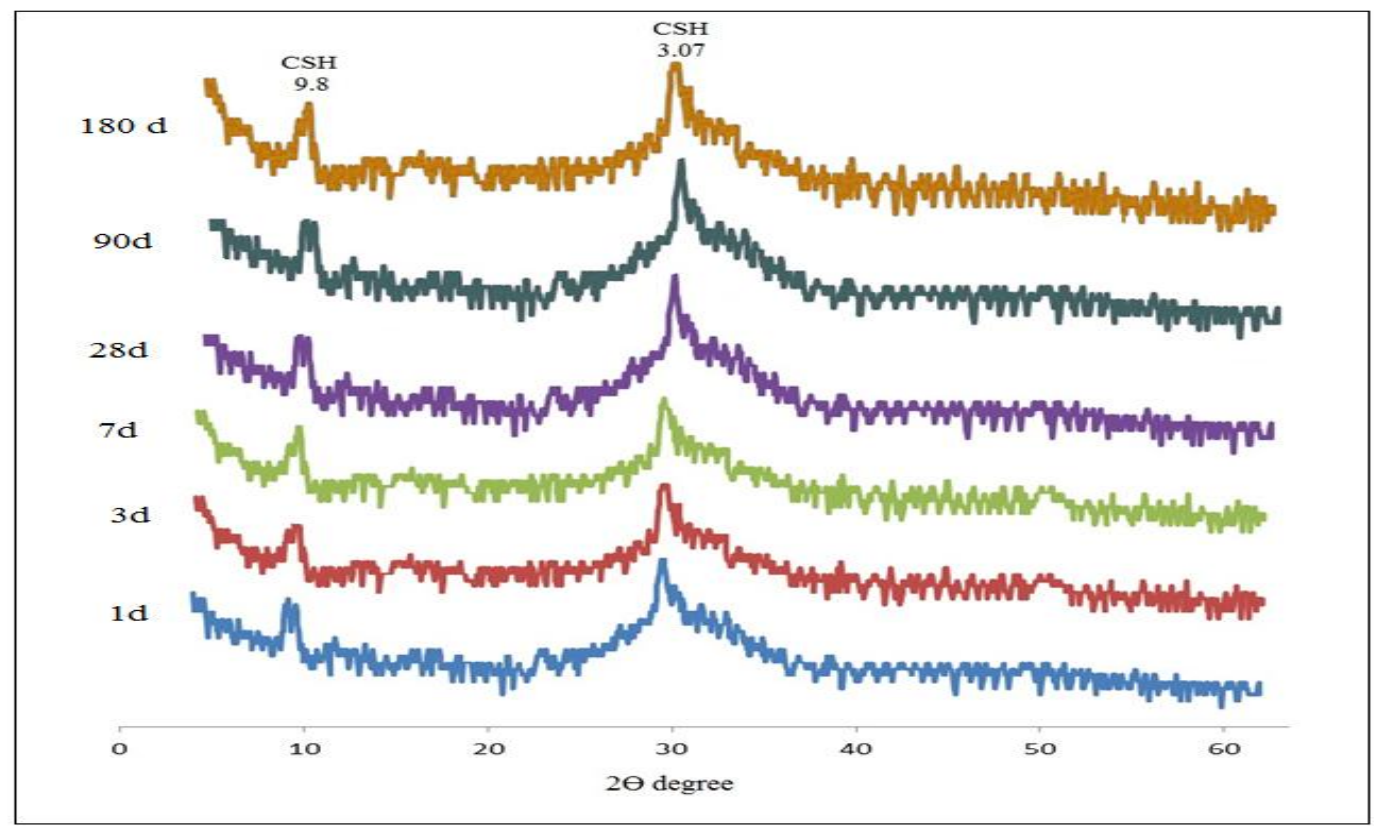


Figure (6): X-ray diffraction patterns for mixes contain (90\% GBFS+10\%CKD) (SD2)

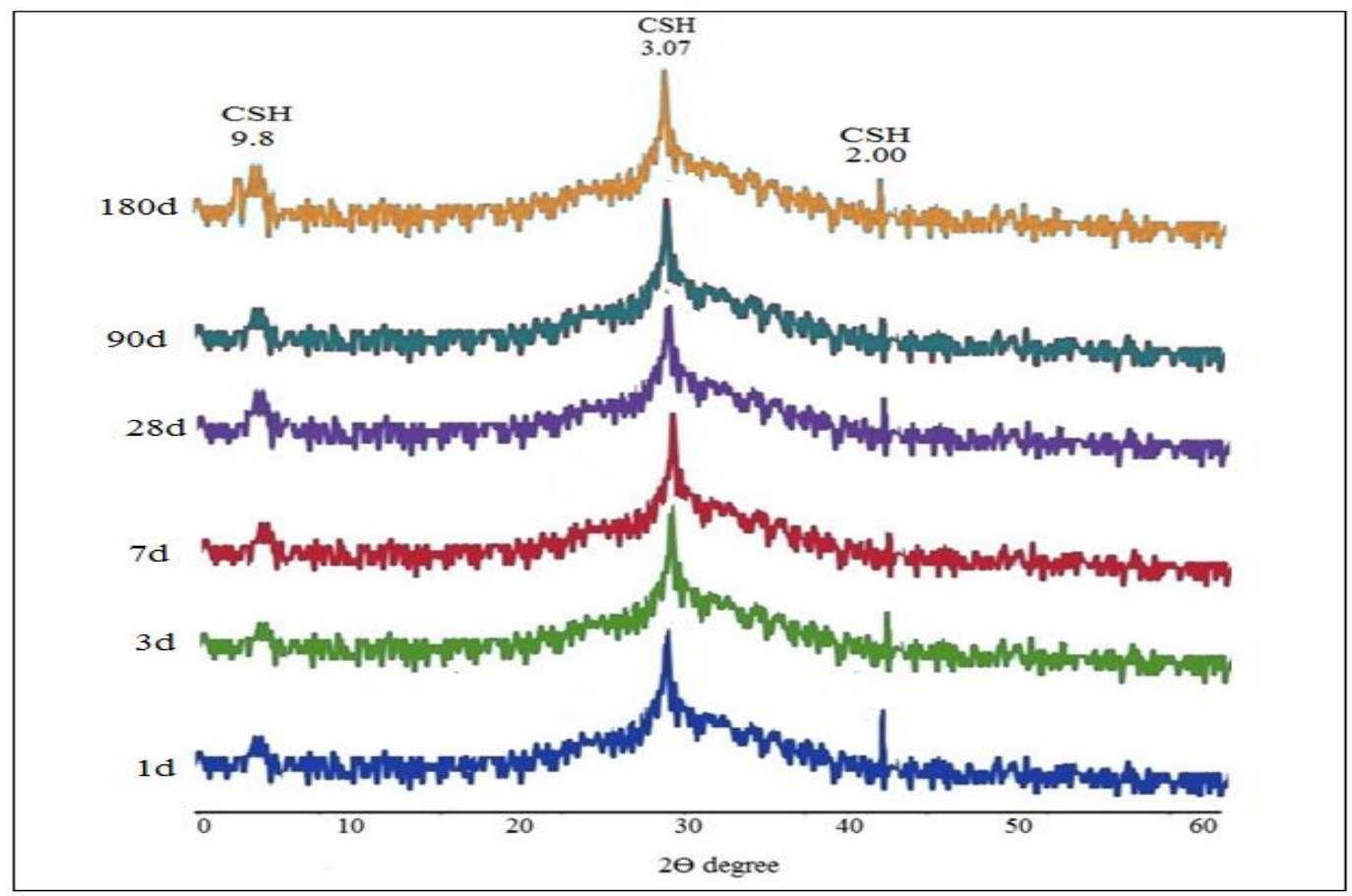

Figure (7): X-ray diffraction patterns for mixes contain

$(85 \%$ GBFS+ $15 \% \mathrm{CKD})(\mathrm{SD} 3)$

\section{III.B. The mixture containing GGBFS and FA}

\section{III.B.1. Compressive strength}

The compressive strength of hardened alkali activated mixes (S,SF1,SF2,SF3 ) cured up to 180 days in water are graphically plotted in Fig. (8). It is clear that the compressive strength increases with curing time due to the formation of more hydration products deposited in the open pores. Therefore, the compressive strength increase. The strength development depends primarily on the formation of hydrated calcium silicate as the main hydration product, which is precipitated into the water filled spaces to form a more compact body with high strength. 


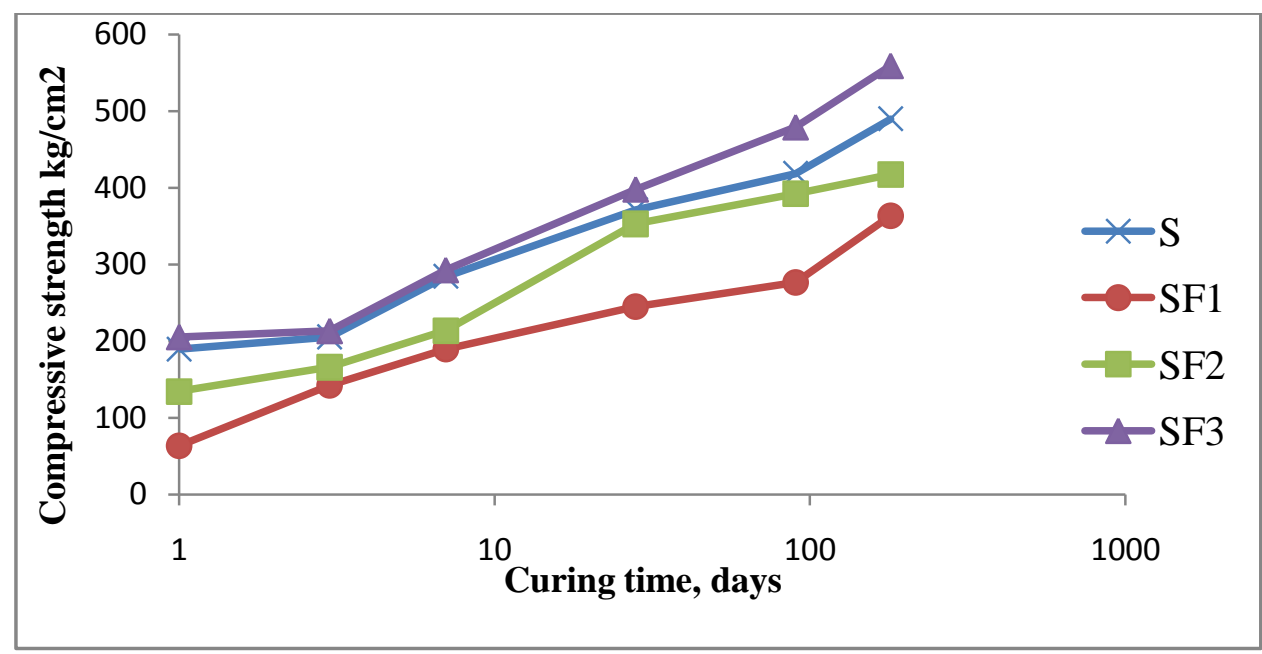

Figure (8): Compressive strength $\left(\mathrm{kg} / \mathrm{cm}^{2}\right)$ of alkali activated GBFS-FA cured up to 180 days.

\section{III.B.2. Chemically combined water content}

Chemically combined water (Wn) contents for mixes (S,SF1,SF2,SF3) cured up to 180 days are graphically plotted in Fig.(9). The Wn content can be adopted as a criterion to evaluate the relative amount of hydration products and the relative hydration degree between different samples with the same kind of hydration products. It is clear that the combined water contents of the alkali activated GBFS pastes gradually increases up to 180 days. This is due to the continuous hydration and accumulation of hydrated products, which deposed in the available open pores. Fig. (9) shows the Wn contents of samples containing GBFS with FA at the ages of 1,3,7,28,90 and 180 days. By addition of FA which have high surface area and fineness that accelerates the rate of hydration forming more hydration products and therefore the chemically combined water contents for mixes increase with time. The mixture containing $15 \%$ FA gave the highest $\mathrm{Wn}$ values.

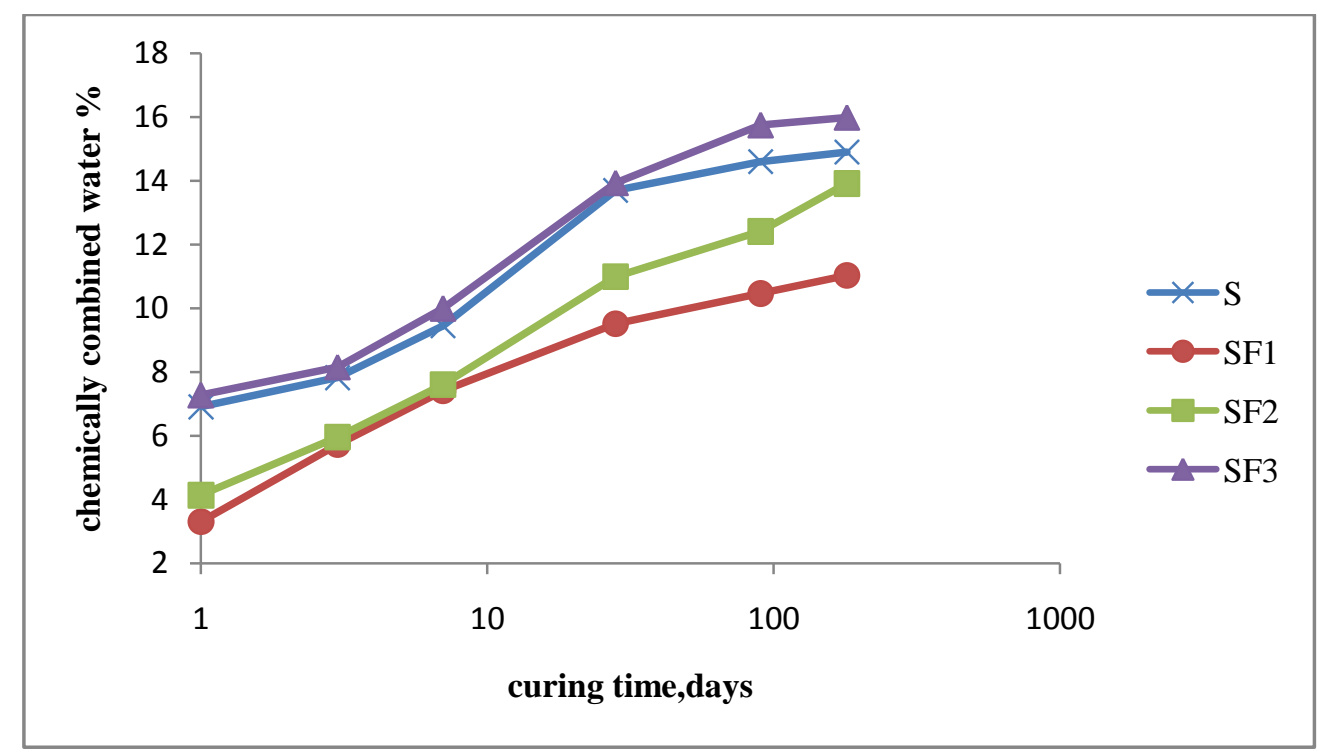

Figure (9): Chemically combined water content (\%) of alkali activated GBFS-FA cured up to 180 days. 


\section{III.B.3. Bulk density}

The bulk density of hardened alkali activated mixes (S,SF1,SF2,SF3 ) cured up to 180 days in water are graphically plotted in Fig. (10). It is found that the bulk density for all mixes increases with curing time, due to the formation of more hydration products which are deposited in some of the open pores then increase the bulk density. As the amount of calcium silicate hydrate increase, the bulk density increase.

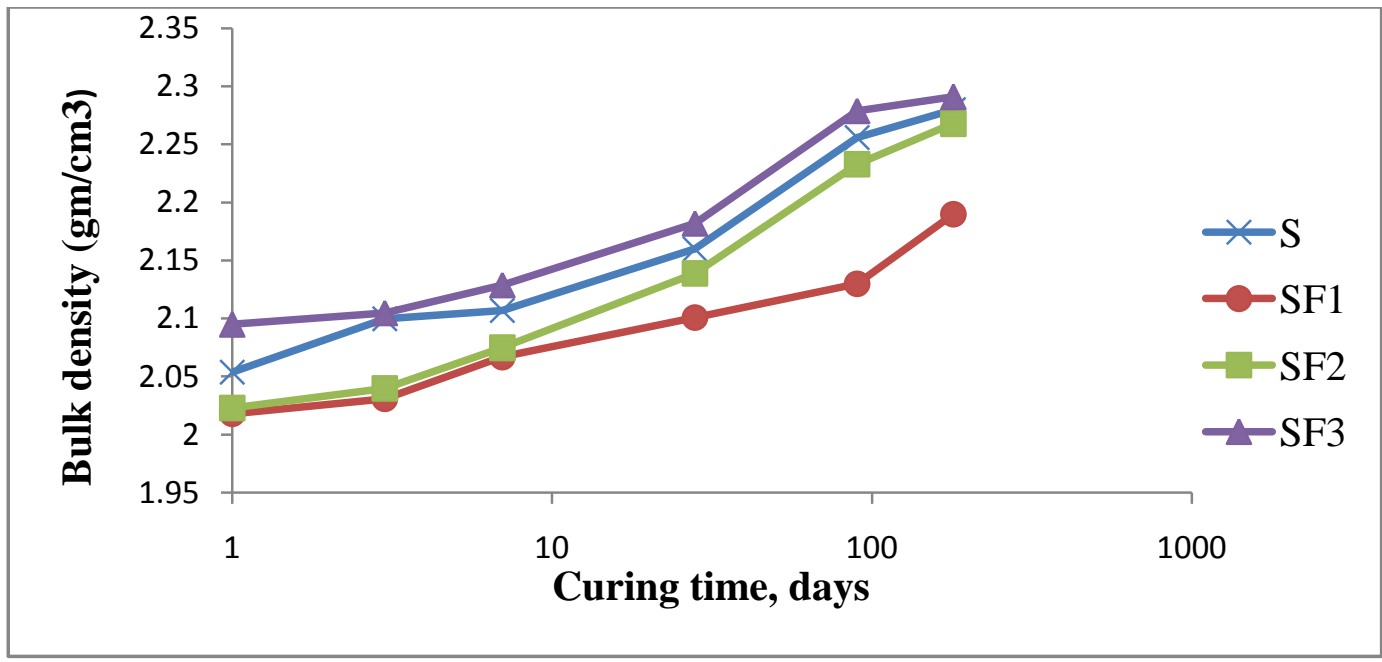

Figure (10): Bulk density $\left(\mathrm{g} / \mathrm{cm}^{3}\right)$ of alkali activated GBFS-FA cured up to 180 day

\section{III.B.4. Total porosity}

The total porosity for mixes (S,SF1,SF2,SF3) are graphically shown in Fig. (11). The total porosity values decrease due to the formation of more hydration products. These hydration products fill a part of the available pore volume of the paste; therefore the total porosity decreases.

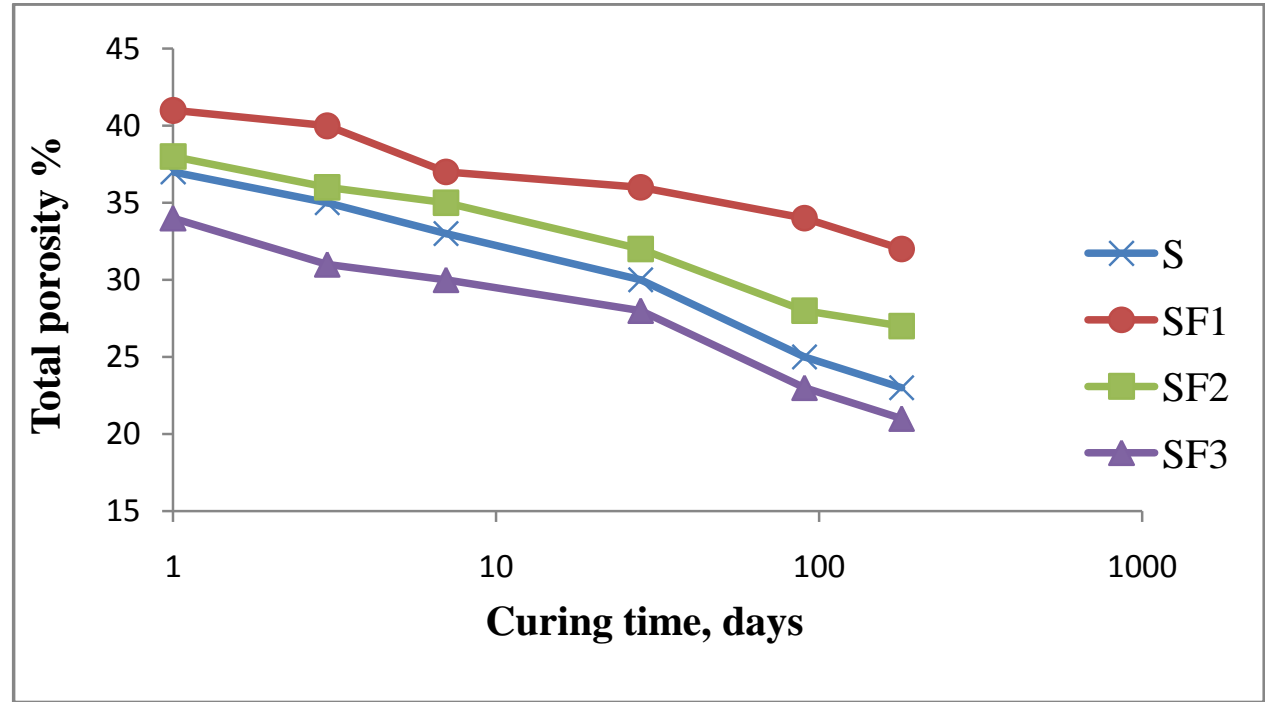

Figure (11): Total porosity (\%) of alkali activated GBFS-FA Cured up to 180 days 


\section{III.B.5. X-ray diffraction analysis}

XRD patterns of alkali activated mixes (SF1, SF2,SF3) are shown in Figs. $(12,13,14)$, It can be observed that the peaks at 9.8 and $3.07 \mathrm{~A}^{\circ}$ changes in the period of curing time at 1 day up to 180 days, suggesting that poor crystalline CSH gel produced in the pastes. Indeed, once GBFS-FA powder is mixed with the alkaline solution, geopolymer gel and CSH gel could be formed after setting and hardening. In alkali activated GBFS-FA, the presence of the strong peak at $d=3.07 \mathrm{~A}^{\mathrm{o}}$ is attributed to $\mathrm{CSH}$ phases, which are composed of calcium silicate hydrate.

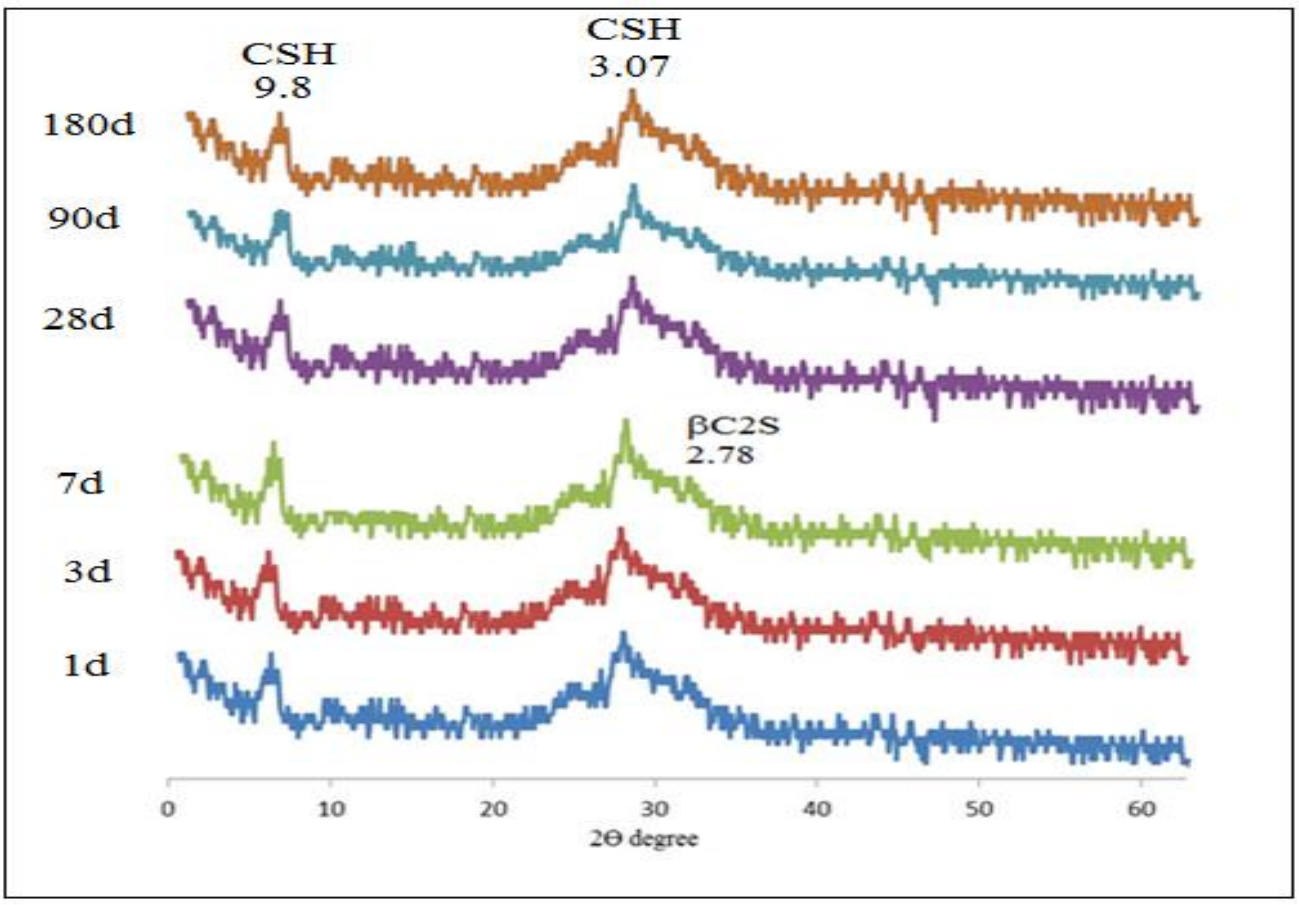

Figure (12): X-ray diffraction patterns for mixes contain (95\% GBFS+5\%FA ) SF1

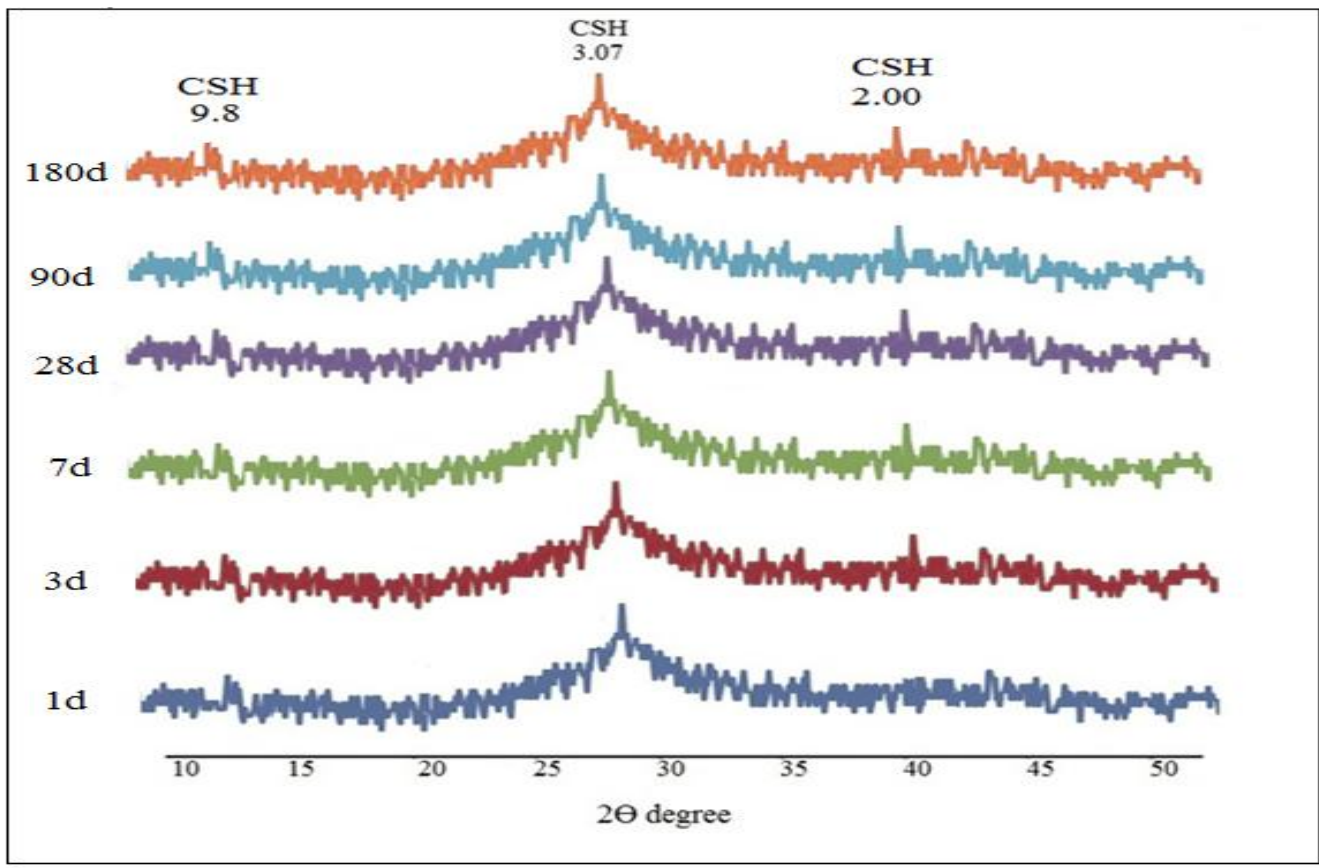


Figure (13): X-ray diffraction patterns for mixes contain (90\%GBFS+10\%FA) SF2

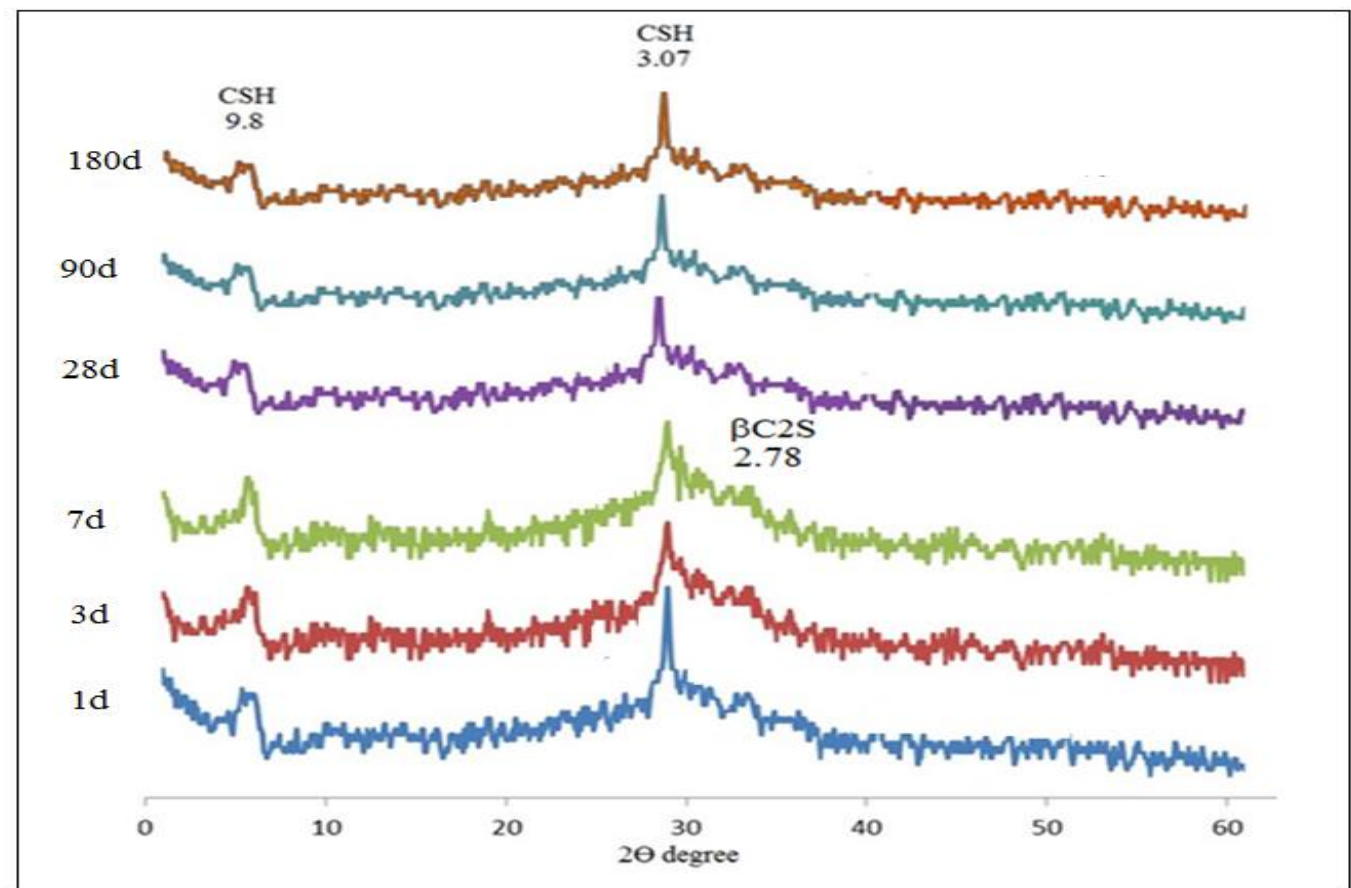

Figure (14): X-ray diffraction patterns for mixes contain (85\%GBFS+15\%FA) SF3

\section{Conclusion}

The main conclusions could be derived from this investigation are summarized as follows:

- The compressive strength of the alkali activated GBFS pastes gradually increases up to 180 days. The combined water contents and bulk density increase while as ,the total porosity decreases with curing time.

- Using 5\% CKD shows better physico chemical and mechanical properties of geopolymer cement than the higher ratios of CKD.

- The results show that the mix SF3 that contain $(85 \%$ slag $+15 \%$ FA) improve the physico chemical and mechanical properties of geopolymer cement compared with the mix containing $100 \%$ slag. 


\section{References}

1. Abdel Gawwad H.A., "Physico-chemical and mechanical studies on alkali activated slag pastes ", Master thesis, Zagazig University, (2010).

2. Badanoiu, A.I., Al-Saadi T.H.A., and Voicu G., "Synthesis and properties of new materials produced by alkaline activation of glass cullet and red mud". International Journal of Mineral Processing, 135, 1-10 (2015).

3. Cement Statistics, " Ecosmart Concrete " http://ecosmartconcrete.com/ page 208 (2000)

4. Crow, JM. "The Concrete Conundrum." Chemistry World, 62-66 http://www.chemistry-world.org March (2008) .

5. Chanh N. V., Trung B. D. and Tuan D. V., "Recent research geopolymer concrete ", The 3rd ACF International Conference -Asian Concrete Federation / Vietnam Concrete Association (2008).

6. Cheng, T.W. and Chiu J.P., "Fire-resistant geopolymer produced by granulated blast furnace slag", Minerals Engineering, 16 , 205 - 210 (2003).

7. Dimas D., Giannopoulou I. and Panias D., "Polymerization in sodium silicate solutions, a fundamental process in geopolymerization technology", J. Mater Sci., 4ㅗ, 3719 (2009).

8. Duchesne J., Duong L., Bostrom T. and Frost R., "Microstructure study of early in situ reaction of fly ash geopolymer observed by environmental scanning electron microscopy (ESEM), Waste Biomass Valor", 1, 367 (2010).

9. Hardjito, D. and Shaw Shen F., "Fly ash-based geopolymer mortar incorporating bottom ash". Modern Applied Science, 4, 44-52 (2012).

10. Rattanasak U. and Chindaprasirt P., "Influence of $\mathrm{NaOH}$ solution on the synthesis of fly ash geopolymer”, Minerals Engineering., 22, 1073 (2009)

11. Tchakouté, H.K., Rüscher, C.H., Kong, S.and Ranjbar, N., "Synthesis of sodium waterglass from white rice husk ash as an activator to produce metakaolin-based geopolymer cements", J. Build. Eng. ㅁ, 252-261 (2016).

12. Tchakouté, H.K., Rüscher, C.H., Kong, S., Kamseu, E.and Leonelli, C., "Geopolymer binders from metakaolin using sodium waterglass from waste glass and rice husk ash as alternative activators", A comparative study Constr. Build. Mater, 114, 276289, (2016). 
13. Yunsheng, Z., Wei S., and Zongjin L., " Composition design and microstructural characterization of calcined kaolin-based geopolymer cement". Applied Clay Science, $\underline{47}$, 271-275 (2010).

14. Zheng G., Xuemin C., Dong H., Jinying P., Guowei M., Shujuan Y and Zhangfa $\mathbf{T}$., "Alkali-activation reactivity of chemosynthetic $\mathrm{Al}_{2} \mathrm{O}_{3}-2 \mathrm{SiO}_{2}$ powders and their 27Al and 29Si magic angle spinning nuclear magnetic resonance spectra", Particuology, 22,151-156 (2015). 


\section{الملخص العربي \\ أسمنت جيوبوليمر مرتكز علي التنشيط القلوي للخبث}

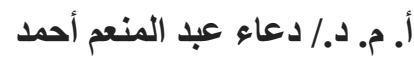

أستاذ مساعد الكيمياء غير العضويه

بكلبه البنات للأداب و العلوم و التربيه

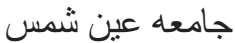

أ. د. دصام عبد العزيز كيشار

أستاذ الكيمياء غير العضويه

بكليه البنات للأداب و العلوم و التربيه

جامعه عين شمس

تم اسنخدام بعض المو اد من البوزو لانا الصناعية مثل حبيبات خبث الفرن العالي، غبار الاسمنت، ورماد الفحم المتطاير

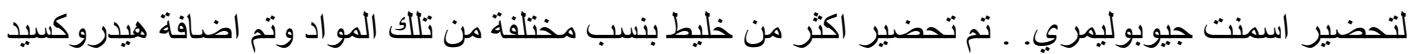

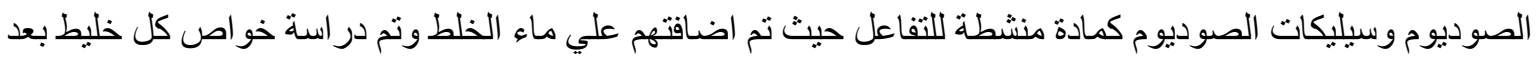

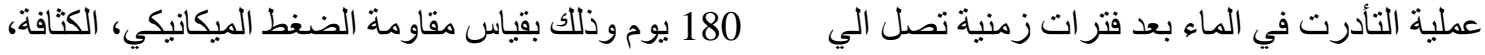

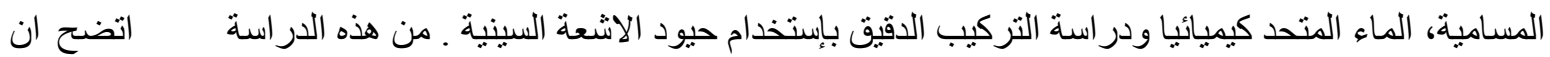

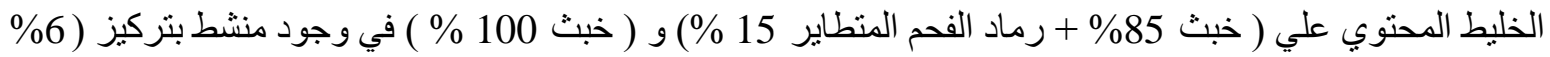
هيدروكسيد صوديوم +10\% سيليكات صوديوم) انسب الخلطات من حيث جميع الخصائص التي تم در استها. 